\title{
5-Hydroxytryptamine - a local regulator of testicular blood flow and vasomotion in rats
}

\author{
O. Collin ${ }^{1,3}$ J-E. Damber ${ }^{2}$ and A. Bergh ${ }^{3 *}$ \\ Departments of ${ }^{1}$ Anatomy, ${ }^{2}$ Urology and Andrology and ${ }^{3}$ Pathology, Umeå University, S-901 87 Umeå, \\ Sweden
}

\begin{abstract}
The effects of 5-hydroxytryptamine $(5-\mathrm{HT}), 5-\mathrm{HT}_{2}$ receptor antagonists (ritanserin and ketanserin), histamine and substance $48 / 80$ on testicular blood flow and microcirculation were studied in adult rats. The substances were administered by topical application on the testicular surface and by intratesticular injections, and blood flow was measured by radioactive microspheres and with a laser Doppler flowmeter. Blood flow was decreased by 5 -HT in a dose-dependent manner and vasomotion in the testis was inhibited, suggesting that it could be involved in the physiological regulation of the testicular vasculature. The 5-HT antagonists did not significantly influence flow or vasomotion in intact testes. Histamine did not cause any major effects on testicular blood flow. Substance 48/80 caused degranulation of testicular mast cells, and reduced testicular blood flow and vasomotion suggesting that testicular mast cells, possibly by releasing $5-\mathrm{HT}$, could be involved in the local control of the testicular vasculature.
\end{abstract}

\section{Introduction}

Total blood flow, vasomotion (spontaneous rhythmical variations in arteriolar blood flow) and vascular permeability in the testis are apparently influenced by factors secreted by Leydig cells and seminiferous tubules (for references see Bergh and Damber, 1993), but the nature of these factors and their physiological and pathophysiological importance is largely unknown. Other cell types in the testis could also be involved in the local regulation of the testicular vasculature. Mast cells, which are a major source of vasoactive substances, and inflammation mediators like 5-hydroxytryptamine (5-HT) and histamine, are present around the subcapsular part of the main testicular artery (Sowerbutts et al., 1986), and mast cells are probably involved in the control of blood flow in other steroid hormone producing organs like the ovary (Krishna et al., 1989) and the adrenal cortex (Hinson et al., 1989). Treatment with hCG causes mast cell degranulation (Morales and Heyn, 1992), and hCG influences blood flow, vasomotion, and vascular permeability in rat testes. Polymorphonuclear (PMN) leucocytes accumulate in testicular venules, and PMNs migrate and macromolecules leak into the interstitial space after hCG/LH administration (Bergh and Damber, 1993). The testis apparently secretes an inflammation mediator in response to hCG or $\mathrm{LH}$, but the cellular source and the nature of this factor(s) is unknown.

Against this background, we examined the role of mast cells and mast cell products in testicular blood flow. 5-HT is secreted by testicular mast cells (Lombard-des Couttes et al., 1974), testicular nerves (Campos et al, 1990), and Leydig cells in

*Correspondence.

Revised manuscript received I September 1995. response to hCG stimulation (Tinajero et al., 1993a, b). Ketanserin (a 5-HT antagonist) inhibits the hCG-induced increase in testicular interstitial fluid volume (Sowerbutts et al., 1986). In addition, 5-HT is known to induce vasoconstriction in the main testicular artery (Free, 1977; Davis, 1992) and high doses cause testicular ischaemia and atrophy (Free, 1977). In addition, it has been demonstrated that 5-HT is an important autocrine or paracrine regulator of Leydig cell function (Dufau et al., 1993; Tinajero et al., 1993a, b) and that Leydig cells play a key role in regulating testicular blood flow (Bergh and Damber, 1993).

\section{Materials and Methods}

\section{Materials}

Radioactive microspheres (16.5 $\pm 0.1 \mu \mathrm{m}$ in diameter) labelled with Cerium-141 were purchased from New England Nuclear Products (Boston, MA). 5-Hydroxytryptamine (5-HT, H-7752), histamine dihydrochloride (H-7250) and Compound 48/80 (C-4257) were purchased from Sigma Chemical Co., St Louis, MO; ritanserin ( $R$ 55667) and ketanserin ( $R$ 49945) were kindly provided by Jansen Research Foundation (Beerse). All substances were dissolved in sterile saline.

\section{Animals}

Adult male Sprague-Dawley rats $(300-350 \mathrm{~g})$ were kept in a controlled laboratory environment. Food and water were available ad libitum. All animals were anaesthetized with pentobarbital $\left(40 \mathrm{mg} \mathrm{kg}^{-1}\right)$, given as a single i.p. injection. During each experiment the animals were kept supine on a heating pad. 
Table 1. Blood flow ( $\left.\mathrm{ml}(100 \mathrm{~g})^{-1} \mathrm{~min}^{-1}\right)$ to testes and various control organs during topical application of drugs to the surface of the left lestis over the main testicular artery in rats

\begin{tabular}{|c|c|c|c|c|c|c|c|c|}
\hline \multirow[b]{2}{*}{ Treatment } & \multicolumn{2}{|c|}{ Testes } & \multicolumn{2}{|c|}{ Epididymis } & \multicolumn{2}{|c|}{ Kidneys } & \multicolumn{2}{|c|}{ Psoas } \\
\hline & Right & Left & Right & Left & Right & Left & Right & Left \\
\hline $100 \mu \mathrm{g}(n=6)$ & $34.3 \pm 5.5$ & $31.8 \pm 2.0$ & $17.9 \pm 2.0$ & $17.8 \pm 2.5$ & $396.5 \pm 97.0$ & $420.7 \pm 115.0$ & $11.6 \pm 3.5$ & $11.3 \pm 2.9$ \\
\hline Histamine $100 \mu \mathrm{g}(n=6)$ & $26.8 \pm 6.6$ & $26.1 \pm 6.0$ & $18.9 \pm 2.0$ & $19.6 \pm 3.9$ & $500.4 \pm 128.1$ & $509.0 \pm 8.4$ & $17.6 \pm 7.2$ & $16.7 \pm 4.9$ \\
\hline $5-\mathrm{HT}$ I0 $\mu \mathrm{g}(n=6)$ & $28.9 \pm 7.7$ & $4.0 \pm 1.6^{*}$ & $25.8 \pm 3.8$ & $23.7 \pm 2.9$ & $396.7 \pm 175.7$ & $410.6 \pm 124.8$ & $22.6 \pm 6.3$ & $18.9 \pm 6.0$ \\
\hline
\end{tabular}

Values are means \pm SEM.

*Significantly different from that in the contralateral testis $P<0.03$.

\section{Measurement of testicular blood flow using radioactive microspheres}

Rats were anaesthetized and the testes were exposed through a scrotal incision. A piece of filter paper $(5 \mathrm{~mm} \times 10 \mathrm{~mm}$ ) was placed over the straight subcapsular part of the main artery on both testes. The test substances, histamine $(100 \mu \mathrm{g})$, substance $48 / 80(100 \mu \mathrm{g}$ or $1000 \mu \mathrm{g})$, or $5-\mathrm{HT}(10 \mu \mathrm{g}$ in $0.1 \mathrm{ml}$ saline) were applied to the filter paper on the left testis and $0.1 \mathrm{ml}$ saline to the right testis. After $30 \mathrm{~min}$, blood flow to various organs was measured using radioactive labelled microspheres as described by Damber and Janson (1977) and Damber (1978). After subsequent collection of a blood sample from the tail artery, the testes, epididymides, kidneys and psoas muscles were dissected out, weighed, and the radioactivity in the samples measured. Blood flow values are given as $\mathrm{ml}$ (100 $\mathrm{g}$ tissue $)^{-1} \mathrm{~min}^{-1}$.

Testes exposed to substance $48 / 80$ were also fixed in $4 \%$ formaldehyde, $3 \%(\mathrm{v} / \mathrm{v})$ glutaraldehyde and $0.05 \%(\mathrm{w} / \mathrm{v})$ picric acid in $0.1 \mathrm{~mol}$ cacodylate buffer $1^{-1}$; postfixed in $1 \%(\mathrm{w} / \mathrm{v})$ $\mathrm{OsO}_{4}$; dehydrated and embedded in Epon (Bergh and Söder, 1990). The morphology of testicular mast cells adjacent to the testicular artery was examined on $1 \mu \mathrm{m}$ toluidine blue stained sections.

\section{Measurement of testicular blood flow and vasomotion using laser Doppler}

Rats were anaesthetized and one testis was exposed via a scrotal incision. The testis was mobilized into a plastic holder and embedded in $3 \%(\mathrm{w} / \mathrm{v})$ agar as described by Hinton et al. (1979) and Setchell et al. (1995). A laser Doppler probe (PF 412, Perimed, Stockholm) was placed over the middle part of the testis not covered by agar and testicular blood flow was measured using a laser Doppler flowmeter ( $\mathrm{PF} 4$, Perimed) as described by Damber et al. (1986). The agar was used to immobilize the testis and in this way avoid artefacts in the blood flow signal owing to movements (Setchell et al., 1995). After a stable blood flow signal with normal vasomotion was observed for $5 \mathrm{~min}$, the testis was injected with test substance in $0.1 \mathrm{ml}$ sterile saline. The injection was made using a 27 gauge needle connected to a $1 \mathrm{ml}$ syringe and took place at the caudal pole of the testis. According to Russel et al. (1987), $50 \mu \mathrm{l}$ of trypan blue injected into the caudal pole of the testis spread
$1 \mathrm{~cm}$ from the injection site in $2 \mathrm{~min}$. Blood flow was then recorded for at least $40 \mathrm{~min}$. In control rats, one testis was injected with $0.1 \mathrm{ml}$ sterile saline.

The following substances and doses were examined:

Substance $48 / 801 \mathrm{ng}, 10 \mathrm{ng}, 100 \mathrm{ng}, 1 \mu \mathrm{g}, 10 \mu \mathrm{g}, 100 \mu \mathrm{g}$. In these rats testicular morphology was examined as described above.

Histamine $1 \mu \mathrm{g}, 10 \mu \mathrm{g}$.

5 -Hydroxytryptamine $0.6 \mathrm{ng}, 6 \mathrm{ng}, 25 \mathrm{ng}, 50 \mathrm{ng}$.

Ketanserin (a $5-\mathrm{HT}_{2}$ antagonist) $50 \mathrm{ng}, 500 \mathrm{ng}, 5 \mu \mathrm{g}, 50 \mu \mathrm{g}$.

Ritanserin (a $5-\mathrm{HT}_{2}$ antagonist) $0.1 \mu \mathrm{g}, 1 \mu \mathrm{g}, 10 \mu \mathrm{g}$, $100 \mu \mathrm{g}$. Ritanserin $(10 \mu \mathrm{g})$ was also injected together with $50 \mathrm{ng}$ 5-HT.

\section{Statistical analyses}

Changes in blood flow after treatment were analysed using the Wilcoxon non parametric test for paired observations and linear correlation. Differences between groups were analysed using the Mann-Whitney $U$ test. The level of significance was set at $P<0.05$.

\section{Results}

Effects of topical application of histamine, substance $48 / 80$ and 5-hydroxytryptamine on the testicular surface over the testicular artery

Substance $48 / 80$ ( $1 \mathrm{mg}$ ) caused a significant decrease in blood flow, but $100 \mu \mathrm{g}$ substance $48 / 80$ was without effect (Table 1 ; it seems as though the contralateral testes in the animals given $1 \mathrm{mg}$ substance $48 / 80$ have an increased flow but this could be related to generally higher organ blood flows in this group). Morphological examination showed that the mast cells were degranulated by both doses (not shown). Topical application of $100 \mu \mathrm{g}$ histamine did not influence testicular blood flow, but application of $10 \mu \mathrm{g} 5$-HT caused a major decrease in testicular blood flow (Table 1). 
Table 2. The percentage decrease in blood flow as measured with a laser Doppler flowmeter and its duration after local injection of different doses of 5-HT in adult rat testes (values are means \pm SEM, $n=4-5$ animals in each group)

\begin{tabular}{lcc}
\hline 5-HT (ng) & $\begin{array}{c}\text { Percentage } \\
\text { decrease } \\
\text { in flow }\end{array}$ & $\begin{array}{c}\text { Duration } \\
\text { of response } \\
\text { (min) }\end{array}$ \\
\hline 0 & $1 \pm 1$ & $3 \pm 1$ \\
0.6 & $13 \pm 2^{*}$ & $2 \pm 1$ \\
6.0 & $23 \pm 2^{*}$ & $13 \pm 2^{*}$ \\
25 & $28 \pm 1^{*}$ & $35 \pm 2^{*}$ \\
50 & $33 \pm 2^{*}$ & $36 \pm 6^{*}$ \\
$50+10 \mu g$ ritanserin & $32 \pm 2^{*}$ & $7 \pm 2^{* \dagger}$ \\
\hline
\end{tabular}

*Significantly different from before treatment $(P<0.05$; Wilcoxon's nonparametric test for paired observations) and after injections of saline $(P<0.05$; Mann-Whitney U test).

${ }^{\dagger}$ Significantly different from after injection of $50 \mathrm{ng} 5-\mathrm{HT}$ alone $(P<0.05$; Mann-Whitney U test).

Effects of intratesticular injections of saline, substance $48 / 80$, histamine, 5-HT and 5-HT antagonists

Saline. Local injection of saline did not significantly influence testicular blood flow (Table 2).

Substance $48 / 80$. Local injection of $100 \mu \mathrm{g}$ substance $48 / 80$ abolished vasomotion and decreased blood flow by $22 \pm 4 \%$ (mean $\pm \mathrm{SEM} ; n=2$ ) for more than $40 \mathrm{~min}$. Injection of $10 \mu \mathrm{g}$ substance $48 / 80$ made the vasomotion pattern irregular and the blood flow was significantly decreased by $11 \pm 2 \%(P<0.05$; mean \pm SEM; $n=5$ ) for $16 \pm 4$ min (mean \pm SEM; $n=5$, Fig. 1 ). The lower doses tested were without effects. Morphological examination revealed that the mast cells were totally degranulated by $100 \mu \mathrm{g}$ substance $48 / 80$, most were degranulated by $10 \mu \mathrm{g}$ substance $48 / 80$, but only a few were partially degranulated by $1 \mu \mathrm{g}$ substance $48 / 80$ (Fig. 2).

Histamine. After local injection of $10 \mu \mathrm{g}$ the blood flow was significantly raised by $15 \pm 2 \% \quad(P<0.05$; mean \pm SEM; $n=5$ ) during $40 \pm 7 \mathrm{~min}$ (mean $\pm \mathrm{SEM}, n=5$ ), but the vasomotion pattern was essentially unaffected. One microgram of substance $48 / 80$ increased flow by $6 \pm 0.5 \%$ (mean \pm SEM; $n=3)$ and vasomotion was unchanged.

5-Hydroxytryptamine. Local injection of 5-HT caused a dose-dependent decrease in blood flow and an inhibition of vasomotion. The duration of the response was also dose dependent (Table 2). Vasomotion was inhibited during the time when flow was reduced (Fig. 3). The linear correlation coefficients between dose of 5-HT and change in blood flow and duration of the response were $0.70(P<0.002)$ and 0.76 $(P<0.001)$, respectively.

5-Hydroxytryptamine antagonist (ritanserin, ketanserin). Neither of the 5- $\mathrm{HT}_{2}$ antagonists showed any significant effect on the testicular blood flow or vasomotion when injected in doses up to $50 \mu \mathrm{g}$. A very large dose of ritanserin $(100 \mu \mathrm{g})$ resulted

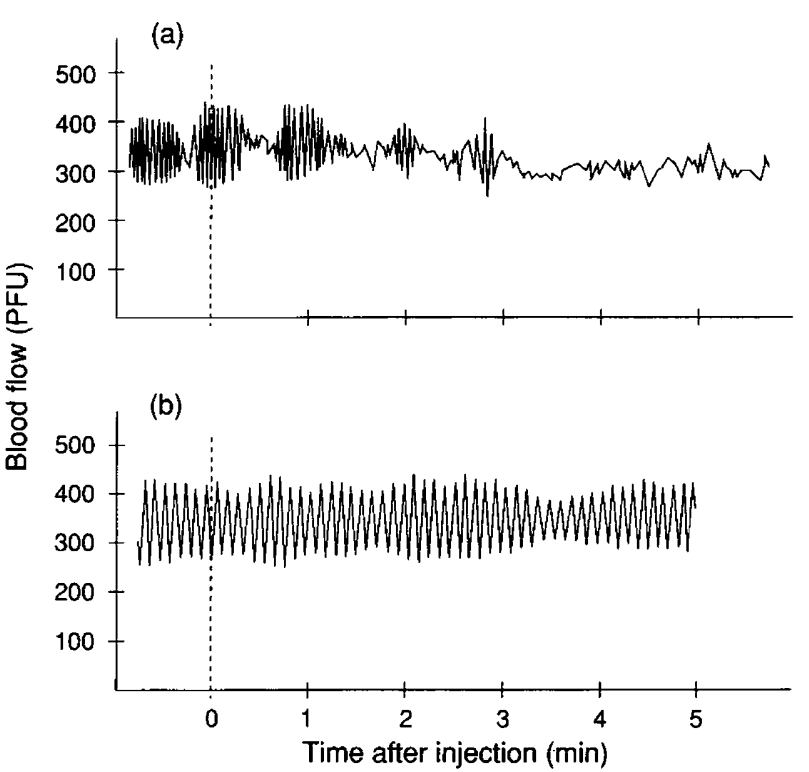

Fig. 1. Blood flow recording (in arbitrary perfusion units, PFU) (a) in a rat testis locally injected with $10 \mu \mathrm{g}$ substance $48 / 80$, and (b) in a rat testis injected with saline. After injection of substance $48 / 80$, blood flow is reduced and vasomotion is irregular. Saline injection did not influence blood flow.

in a slightly decreased blood flow and an irregular vasomotion. However, an injection of $50 \mathrm{ng} 5-\mathrm{HT}$, after the testis had received $10 \mu \mathrm{g}$ ritanserin, caused a similar decrease in blood flow to that without ritanserin, but the time for restoration of normal blood flow was markedly reduced (Table 2), demonstrating that the 5-HT antagonist was effective.

\section{Discussion}

In this study we used two different methods to deliver substances to the testis. Considerably higher doses were apparently needed to induce effects after topical than after intratesticular administration. This indicates that most of the topically applied substance does not reach the testis and for this reason conclusions are based mainly on the experiments in which the test substances were injected into the testis.

One aim of this study was to evaluate the role of testicular mast cells in the local regulation of testicular blood flow and microcirculation. Degranulation of testicular mast cells with substance $48 / 80$ (Irman-Florjanc and Erjavec, 1983) results in a moderate decrease in blood flow and an inhibition of vasomotion. Rat mast cells contain several factors that may influence blood flow, including histamine and 5-HT (Lombard des-Couttes et al., 1974). Histamine apparently does not have a pronounced influence on testicular blood flow (only very high doses caused a slight increase). In contrast, 5-HT caused a dose-dependent decrease in blood flow. It is therefore not unlikely that the effect of substance $48 / 80$ could be mediated by release of $5-\mathrm{HT}$ from testicular mast cells. The physiological regulation of testicular mast cell secretions is unknown, but their numbers are increased in infertile testes (Nagai et al., 1992). Morales and Heyn (1992) suggested that hCG treatment causes degranulation of testicular mast cells $6 \mathrm{~h}$ and $24 \mathrm{~h}$ after 

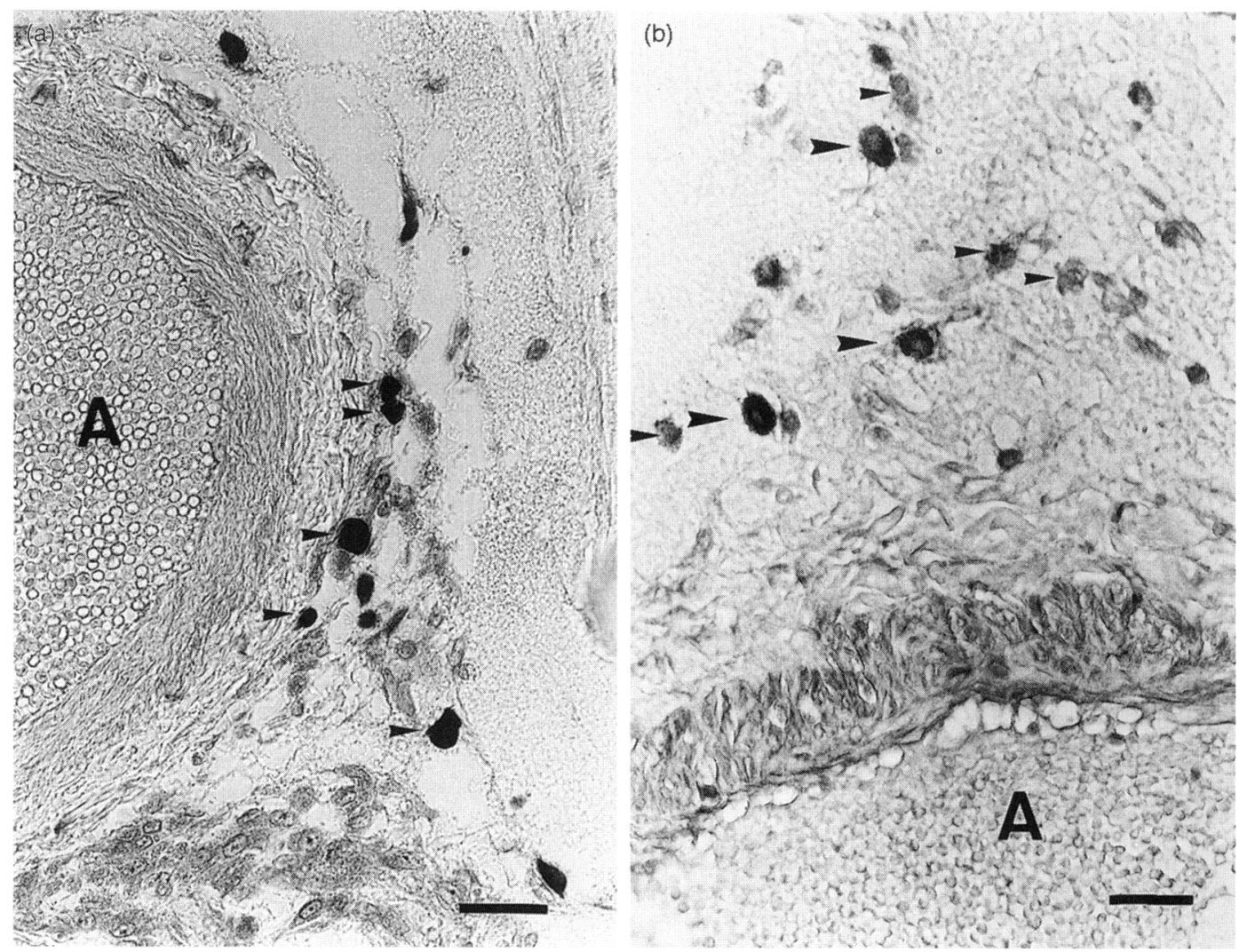

Fig. 2. Sections showing the tissue adjacent to the subcapsular part of the rat testicular artery $(A)$, in (a) a control animal and (b) $20 \mathrm{~min}$ after local injection of $10 \mu \mathrm{g}$ substance $48 / 80$. Several mast cells with numerous granules are observed in the control testis (arrowheads) but only degranulated (small arrowheads) or degranulating cells (large arrowheads) were observed after administration of substance $48 / 80$. Scale bars represent $25 \mu \mathrm{m}$.

treatment, a response apparently analogous to the adrenocorticotropic hormone- and LH-induced mast cell degranulation in the adrenal cortex (Hinson et al, 1989) and ovary (Krishna et al., 1989), respectively. Testicular blood flow is decreased $6 \mathrm{~h}$ after LH/hCG treatment (van Vliet et al., 1988; Widmark et al., 1989), but whether this is related to release of 5-HT remains unknown. Treatment with LH/hCG also induces an inflammation-like increase in vascular permeability in the testis (Bergh and Damber, 1993), but this response is probably not related to release of mast cell products like 5-HT and histamine, since local injection of these substances into the testis does not influence vascular permeability (Bergh and Söder, 1990; Setchell et al., 1988).

The concentration of $5-\mathrm{HT}$ in rat plasma is reported to be $3.9 \mathrm{ng} \mathrm{ml}^{-1}$ and in testicular interstitial fluid to $23 \mathrm{ng} \mathrm{ml}^{-1}$ (Campos et al., 1990). The high content in interstitial fluid could be an overestimation, as 5-HT could have been released from cells during the collection of interstitial fluid (Maddocks and Setchell, 1988). Testicular 5-HT probably originates from at least three different sources: testicular mast cells (Lombard-des Couttes et al., 1974), testicular nerves (Campos et al., 1990) and Leydig cells (Tinajero et al., 1993b). The relative contributions from these sources are unknown, and there is no information available on whether intratesticular 5-HT concentration in vivo is influenced by physiological regulators of testicular function. The only information available is that denervation reduced intratesticular 5-HT by 34\% (Campos et al., 1990). It has been shown, however, that 5-HT could be an important autocrine or paracrine regulator of Leydig cell function (Dufau et al., 1993; Tinajero et al., 1993a, b). It is secreted by Leydig cells in response to hCG stimulation in vitro; Leydig cells have 5-HT receptors and 5-HT, by increasing Leydig cell corticotrophin releasing factor secretion, inhibits Leydig cell testosterone secretion (Tinajero et al., 1993). In addition, 5-HT could be an important regulator of testicular blood flow. Local injection of 5-HT, in doses similar to the testis content, decreased in a dose-dependent way testicular blood flow and inhibited vasomotion. Local injection of the 5-HT antagonist into intact testes did not, however, induce any significant changes in blood flow, perhaps suggesting that, under basal conditions, 5-HT is stored in cells and is only released when needed. Studies have shown that 5-HT causes constriction of the subcapsular testicular artery (Free, 1977; Davis, 1992; Setchell et al., 1988), and we have confirmed this observation in vivo with microscopy (O. Collin, J-E. Damber and A. Bergh, unpublished). The present observation that 5-HT inhibits vasomotion indicates that it also influences smaller intratesticular arterioles.

Indirect evidence suggests that the testis could be particularly susceptible to reductions in blood flow. The oxygen concentration in the seminiferous tubules is low and owing to the long and rather narrow artery, capillary pressure in the testis is only marginally higher than venous pressure (Setchell, 1990; Sweeney et al., 1991). Moderate reductions in capillary 


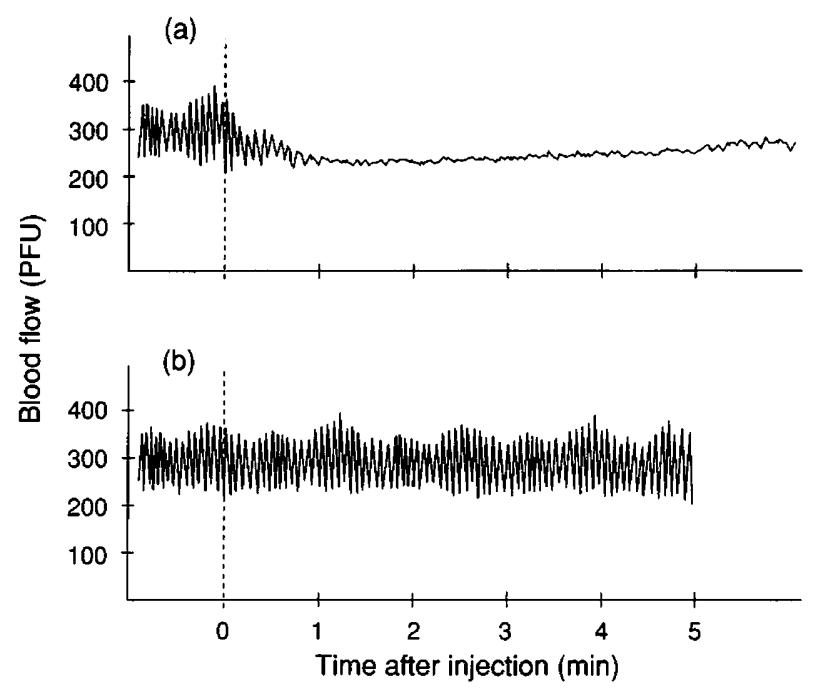

Fig. 3. Blood flow recording (in arbitrary perfusion units, PFU) (a) in a testis injected with $6 \mathrm{ng} 5-\mathrm{HT}$, and $(\mathrm{b})$ in a testis injected with saline. Almost immediately after 5-HT injection (!), flow is reduced and vasomotion inhibited. Saline injection did not influence blood flow.

pressure and inhibition of vasomotion (vasomotion facilitates transvascular fluid exchange; Intaglietta, 1988) could consequently have adverse effects on the testis (Bergh and Damber, 1993). The observations that the testis produces 5-HT and that it is particularly sensitive to this vasoconstrictor could therefore be of importance for testicular pathophysiology. 5 -HT is released during stress; it is increased in the testis in pathological conditions such as varicocele and during treatment with drugs like propanolol (Dufau et al., 1993; Tinajero et al., 1993b) and previous studies have demonstrated testicular atrophy after administration in high doses (see Free, 1977). The testis also produces another highly potent vasoconstrictor, endothelin-1, in response to hCG stimulation (Collin et al, unpublished) and in other vascular beds endothelin- 1 and 5-HT have synergistic effects (Yang et al., 1990, 1992). Stimulation of rat testis with high doses of hCG may induce focal degeneration of seminiferous tubules (van Vliet et al., 1988), but it remains to be shown whether this could be caused by an hCG-induced secretion of locally produced vasoconstrictors.

This study was supported by grants from the Swedish Medical Research Council (project no. 5935) and the Maud and Birger Gustavsson Foundation. The 5-HT antagonists were kindly donated by Jansen Research Foundation. Skilful technical assistance was provided by S. Kilter.

\section{References}

Bergh A and Damber J-E (1993) Vascular controls in testicular physiology. In Molecular and Cellular Endocrinology of the Male Reproductive System pp 439-468 Ed. DM deKretser. Academic Press, New York

Bergh A and Söder O (1990) Interleukin I beta but not interleukin 1 alpha induces acute inflammation-like changes in the testicular microcirculation of adult rats Journal of Reproductive Immunology 17 155-165

Campos MB, Vitale ML, Calandra RS and Chiocchio SR (1990) Serotonergic innervation of the rat testis Journal of Reproduction and Fertility $\mathbf{8 8}$ $475-479$
Damber J-E (1978) 'Testicular blood flow: methodological and functional studies in the rat Umea University Medical Dissertation Newseries 39 1-43

Damber J-E and Janson P-O (1977) Testicular blood flow and testosterone concentrations in spermatic venous blood of anaesthetized rats Journal of Reproduction and Fertility 52 265-269.

Damber J-E, Bergh A, Fagrell B, Lindahl O and Rooth P (1986) Testicular microcirculation in the rat studied by videophotometric capillaroscopy, fluorescence microscopy and laser Doppler flowmetry Acta Physiologica Scandinavica 126 371-376

Davis JR (1992) Comparison of norepinephrine and 5-HT vasoconstriction of the rat isolated testicular artery at physiological and elevated transmural pressure Biology of Reproduction $47692-697$

Dufau ML, Tinajero JC and Fabbri A (1993) Corticotrophin-releasing factor: an antireproductive hormone of the testis. FASEB Journal 7 299-307

Free M) (1977) Blood supply to the testis and its role in local exchange and transport of hormones. In The Testis vol. iv pp 39-90 Eds AD Johnson and WR Gomes. Academic Press, New York

Hinson JP, Vinson GP, Pudney J and Whitehouse BJ (1989) Adrenal mast cells modulate vascular and secretory responses in the intact adrenal gland of the rat Journal of Endocrinology 121 253-258

Hinton BT, Dott HM and Setchell BP (1979) Measurement of motility of rat spermatozoa collected by micropuncture from the testis and from different regions along the epididymis Journal of Reproduction and Fertility 55 227-229

Intaglietta M (1988) Arteriolar vasomotion: normal physiological activity or defence mechanism Diabetes and Metabolism 14 486-494

Irman-Florjanc T and Erjavec F (1983) Compound $48 / 80$ and substance $P$ induced release of histamine and 5-HT from peritoneal mast cells Agents Actions 13 134-14I

Krishna A, Beesley K and Terranova PF (1989) Histamine, mast cells and ovarian function Journal of Endocrinology 120 363-371

Lombard-des Couttes MN, Falk B, Owman CH, Rosengren E, Sjöberg NO and Walles B (1974) On the question of content and distribution of amines in the rat testis during development Endocrinology 95 1746-1749

Maddocks S and Setchell BP (1988) The composition of extracellular interstitial fluid collected with a push-pull cannula from the testis of adult rats journal of Physiology 407 363-372

Morales BA and Heyn R (1992) HCG induces degranulation in testicular mast cells. 9th workshop on Development and function of the reproductive organs Ares Serono Symposia 40568

Nagai T, Takaba H, Miyake K, Hirabayashi Y, Yamada K (1992) Testicular mast cell heterogeneity in indiopathic male infertility Fertility and Sterility 57 1331-1336

Russel DL, Saxena KN and Weber EJ (1987) Intratesticular injection as a method to assess the potential toxicity of various agents and to study mechanisms of normal spermatogenesis Gamete Research 17 43-56

Setchell BP (1990) Local controls of testicular fluids Reproduction, Fertility and Development 2 291-309

Setchell BP, Sowerbutts SF and Zupp IL (1988) The failure of 5-hydroxytryptamine (serotonin) or histamine to increase vascular permeability in the rat testis Biology of Reproduction 3886 Abstract 114

Setchell BP, Bergh A, Widmark A and Damber J-E (1995) Effect of temperature of the testis on vasomotion and blood flow International journal of Andrology 18 $120-126$

Sowerbutts SF, Jarvis LG and Setchell BP (1986) The increase in testicular vascular permeability induced by human chorionic gonadotrophin involves 5-hydroxytryptamine and possibly oestrogens but not testosterone, prostaglandins, histamine or bradykinin Australian Journal of Experimental Biology and Medical Science 64 137-147

Sweeney TE, Rozum JS, Desjardins C and Gore RW (1991) Microvascular pressure distribution in the hamster testis American Journal of Physiology 260 H1581-H1589

Tinajero JC, Fabbri A and Dufau ML (1993a) Serotonergic inhibition of rat Leydig cell function by propanolol Endocrinology $133257-264$

Tinajero JC, Fabbri A, Ciocca DR and Dufau ML (1993b) 5-HT secretion from rat Leydig cells Endocrinology 133 3026-3029

van Vliet J, Rommerts FFG, de Rooij DG, Buwalda G and Wensing CJG (1988) Reduction of testicular blood flow and focal degeneration of tissue in the rat after administration of human chorionic gonadotrophin Journal of Endocrinology $11751-57$

Widmark A, Damber J-E and Bergh A (1989) High and low doses of luteinizing hormone induce different changes in testicular microcirculation Acta Endocrinologica $121621-627$ 
Yang Z, Richard V, von Segesser L, Bauer E, Stulz. P, Turina M and Lucher TF (1990) Threshold concentrations of endothelin-1 potentiate contractions to norepinephrine and 5-HT in human arteries Circulation 82 188-195
Yang BC, Nichols WW, Lawson DL and Mehta JL (1992) 5-Hydroxytryptamine potentiates vasoconstrictor effects of endothelin-1 American Journal of Physiology 262 H931-H936 